\title{
The impact of competitive sports on menstrual cycle and menstrual disorders, including premenstrual syndrome, premenstrual dysphoric disorder and hormonal imbalances
}

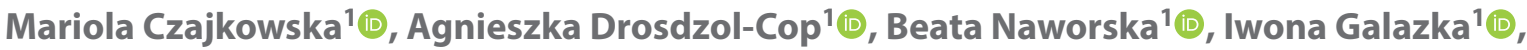

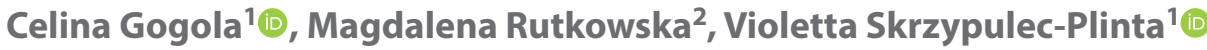 \\ ${ }^{1}$ Women's Health Chair, School of Health Science, Medical University of Silesia, Katowice, Poland \\ ${ }^{2}$ Chair of Physiotherapy, School of Health Science, Medical University of Silesia, Katowice, Poland
}

\begin{abstract}
Objectives: With the considerable increase of female participation in youth sports, it has become crucial for medical professionals, coaches and parents to improve their competitiveness by understanding the conditions for which these females are at elevated risk and mitigating possible health consequences.

The aim of this study was to evaluate the effect competitive sports have on the disorders of the menstrual cycle, to investigate the frequency of PMS (premenstrual syndrome)/PMDD (premenstrual dysphoric order) in professional female athletes and to identify risk factors predisposing for PMS and PMDD. Additionally, the levels of selected hormones such as serum estradiol, FSH, LH and prolactin were investigated to identify any hormonal perturbances that might have influence or be the risk factors for menstrual dysfunctions.
\end{abstract}

Material and methods: The study group consisted of 75 professional athletes (girls and young women at the age of 16-22) who lived on the territory of Silesia. The control group consisted of 50 girls and young women at the same age, who did not practice any sport. The research tools included daily diary of PMS symptoms created in line with The American College of Obstetricians and Gynecologists (ACOG) recommendations and ICD-10 diagnostic criteria, daily diary of PMDD symptoms created according to DSM-V diagnostic criteria of the American Psychiatric Association (APA) and premenstrual symptoms screening tool (PSST).

Results: The analysis of menstrual cycle disorders showed statistical significance for heavy menstrual bleeding $(p=0.01)$ and longer breaks between menstrual bleeds $(p=0.01)$. PMDD was diagnosed in $8 \%$ and PMS in more than $42 \%$ of respondents. The incidence of PMDD was not at significant variance between the groups (9.33\% in contrast to $6.0 \%)$, while incidence of PMS was statistically different in both groups $(p=0.045)(49.33 \%$ vs $32.0 \%)$. A significant correlation between PMS, average age $(p=0.00001)$ and menarche age $(p=0.03)$ in young active athletes has been shown. The risk of PMS increased with age (by 1.71 with each year) $(p=0.0007)$.

Conclusions: A number of other risk factors predisposing for PMS and PMDD has also been identified. The findings of these researches will enable the athletic care network to provide better care for young female athletes.

Key words: menstruation cycle; menstrual disorders; premenstrual syndrome; premenstrual dysphoric disorder; sex hormones

Ginekologia Polska 2020; 91, 9: 503-512

\section{INTRODUCTION}

Over the past several decades there has been a dramatic increase in youth sport participation. The number of female athletes skyrocketed: a 2012 longitudinal national survey found that the number of high school aged girls participating in competitive sport has increased tenfold [1].
Unsurprisingly, girls and young women benefit from engaging in sport activities; they better their health and life skills as well as uncover their passions [2]. It is also important because it increases their self-confidence. The direct relationship between athletics and women in leadership roles has been proved by a 2013 Erst and Young survey of 
821 high-level executives, which demonstrated that $96 \%$ of the women in chief executive positions had played sport [3].

However, engaging in sport can also be a risk factor for unhealthy behaviours, high training loads and metabolic disturbances in a subset if vulnerable athletes [4]. An official document entitled Female Athletes Issues for the Team Physician: A Consensus Statement - 2017 Update confirms that female athletes suffer musculoskeletal injuries and medical problems that come from and/or impact athletic activity. It also highlights that team physicians are required to recognize the gender-specific ramifications of a number of issues including menstrual dysfunctions because in the athlete, it is at the minimum two to three times more frequent than in the non-athlete. Female athletes are also at higher risk of primary and secondary amenorrhea [5].

Long-term training periods or participation at competitions also weaken ovarian activity, which can manifest as luteal phase defect, irregular menstruation or amenorrhea. Regular intensive physical activities activate hypothalamic-pituitary-adrenal axis, lower thyroid hormones, leptin, insulin growth factor and the secretion of growth hormone. Stress that usually accompanies competitions is yet another factor which intensifies menstrual disorders in girls and women who train intensively. Stress reaction causes changes in the cyclic and pulsatile secretion of $\mathrm{GnRH}$, lowers the concentration of gonadotropins, raises the level of prolactin, growth hormone, testosterone, ACTH, adrenal steroids and endorphins $[6,7]$.

Moreover, epidemiologic studies showing that $15-20 \%$ of the general population of women of reproductive age meet the criteria of high susceptibility to PMS (premenstrual syndrome) and $3-8 \%$ of them meet PMDD (premenstrual dysphoric disorder) exposure conditions [8-10] which indicates the need to investigate whether practicing competitive sport might also be a risk factor for PMS and PMDD. These findings might prove important for athletes, parents, coaches and care providers to recognize and mitigate risks associated with the participation and be aware of the practicality of prevention and early detection of menstrual dysfunction to prevent serious health consequences.

The aim of this study was to evaluate the impact of practicing competitive sports on menstrual cycle disorders, to investigate the frequency of PMS/PMDD in female professional athletes and to identify risk factors predisposing for PMS and PMDD. Additionally, the levels of selected hormones such as serum estradiol, FSH, LH and prolactin were investigated to identify any hormonal perturbances that might have influence or be the risk factors for menstrual dysfunctions. The findings were intended to aid the development of more effective prevention, early detection and treatment strategies for menstrual problems in female athletes.

\section{MATERIAL AND METHODS}

\section{Study population}

The prospective study involved 125 girls and young women (16-22 years of age). The study group consisted of 75 female professional athletes (girls and young women). The inclusion criteria: obtaining the informed consent for the examination, menstrual bleeds for notes than 2 years, the absence of systemic diseases, including endocrine disorders, depressive, anxiety and personality disorders. Girls and young women were members of sport clubs and/or students of sport schools. They practiced athletics, including medium and long-distance runs. They were subject to two endurance improving training methods: continuous method and interval method, with diversification into light, moderate and heavy training loads and unification of exercise duration.

To be classified as a professional athlete the subject had to be a member of a sport club, take part in championships and attend minimum 4 two-hour trainings per week.

The control group consisted of 50 girls and young women who were not practicing any sports.

The mean age was $18.7 \pm 1.9$ years in the study group, and $18.5 \pm 1.8$ years in the control group. The difference was statistically insignificant. The study and control groups were also homogenous in terms of height and menarche age. Body weight was statistically significant $(p=0.001)$ while body mass index (BMI) was statistically insignificant between the groups (Tab. 1).

\section{Research methods}

The research tools included a questionnaire to obtain information about social and demographic characteristics, family history, the course of menstruation cycle, obstetrical and gynecological history, gynecological diseases, type of sport practiced, the time and intensity of trainings, life style, diet, stimulants used, present health condition, current medications and the occurrence of PMS and PMDD symptoms.

Daily diary of PMS symptoms has been created in accordance with The American College of Obstetricians and Gynecologists (ACOG) recommendations and ICD-10 diagnostic criteria. ACOG asserts that PMS cannot be diagnosed unless one of the six psychological symptoms (depression, angry outbursts, irritability, anxiety, confusion, social withdrawal) or one of the four physical symptoms (breast tenderness, abdominal bloating, headache, swelling of extremities) is observed. In order to diagnose PMS, the symptoms must present themselves 5 days before the menstruation period in every of the two successive menstrual cycles (prospectively), they must lessen in 4 days following the onset of menstruation and cannot reappear until at least $13^{\text {th }}$ day of menstruation cycle.

Everyday diary of PMDD symptoms has been developed according to diagnostic criteria of the American Psychiatric 


\begin{tabular}{|c|c|c|c|c|c|c|c|}
\hline Values & Group & Mean & Standard deviation & Median & $5^{\text {th }}$ percentile & $95^{\text {th }}$ percentile & $\begin{array}{l}\text { Mann-Whitney's } \\
\text { U test }\end{array}$ \\
\hline \multirow{2}{*}{ Age [years] } & Studied & 18.7 & 1.9 & 18.0 & 16.0 & 21.3 & \multirow{2}{*}{ NS $(p=0.40)$} \\
\hline & Control & 18.5 & 1.8 & 20.0 & 16.0 & 20.6 & \\
\hline \multirow{2}{*}{ Height $[\mathrm{cm}]$} & Studied & 170 & 6 & 171 & 158 & 178 & \multirow{2}{*}{ NS $(p=0.18)$} \\
\hline & Control & 169 & 6 & 170 & 159 & 178 & \\
\hline \multirow{2}{*}{ Body weight [kg] } & Studied & 58.1 & 6.2 & 59.0 & 45.8 & 68.0 & \multirow{2}{*}{$p=0.001$} \\
\hline & Control & 62.6 & 8.7 & 62.5 & 47.0 & 73.6 & \\
\hline \multirow{2}{*}{ BMI } & Studied & 20.01 & 1.82 & 19.82 & 16.96 & 22.66 & \multirow{2}{*}{ NS $(p=0.55)$} \\
\hline & Control & 21.84 & 2.64 & 21.30 & 18.11 & 26.49 & \\
\hline \multirow{2}{*}{ Menarche } & Studied & 13.3 & 1.4 & 13.0 & 11.0 & 15.0 & \multirow{2}{*}{ NS $(p=0.06)$} \\
\hline & Control & 12.9 & 1.2 & 13.0 & 11.0 & 15.0 & \\
\hline
\end{tabular}

$\mathrm{BMI}$ - body mass index; NS — not significant

Association (APA) — DSM-IV (Diagnostic and Mental Disorders) [11-14].

Each subject had her estradiol, FSH, PH and PRL levels investigated. For this purpose, they had $5-6 \mathrm{~mL}$ of peripheral venous blood collected. Serum was separated by centrifugation of venous blood clots collected into a dry tube by a CENTRIFUGE MPW 340 (3000 revolutions, 8 minutes) device. Until biochemical analysis, centrifuged blood was stored in eppendorfs and frozen at $\left(-20^{\circ} \mathrm{C}\right)$.To avoid false positive results the blood was collected in the morning, after night rest, between the $2^{\text {nd }}$ and $5^{\text {th }}$ day of menstruation cycle, after fasting and following a 12 hour break from the gymnastic exercises. The stimulation of nipples was avoided 8-12 hours before the test.

The concentration levels of estradiol, FSH, LH and prolactin in accordance with the norm for follicular phase were determined using Abbot ARCHITECT CMIA (chemiluminscencemicroparticle immunoassay) diagnostics. The precision of ARCHITECT Estradiol is $\leq 5 \mathrm{pg} / \mathrm{mL}$ for concentrations in the range of the low control (target $45 \mathrm{pg} / \mathrm{mL}$ ) and $\leq 7 \%$ for concentrations in the range of the medium control (target $190 \mathrm{pg} / \mathrm{mL}$ ) and high control (target $600 \mathrm{pg} / \mathrm{mL}$ ). The analytical sensitivity of ARCHITECT Estradiol is $\leq 10 \mathrm{pg} / \mathrm{mL}$.

The ARCHITECT FSH test has been developed to ensure the precision expressed by the total value of coefficient of variation of $\leq 10 \%$ for concentrations on the range of the low, medium and high control. Analytical sensitivity of Architect FSH is below $0.05 \mathrm{~m} \mathrm{IU} / \mathrm{mL}$. The precision of ARCHITECT LH is $\leq 10 \%$ of the total coefficient of variation. Analytical sensitivity of Architect LH is below $0.07 \mathrm{~m} \mathrm{IU} / \mathrm{mL}$. Analytical sensitivity of ARCHITECT Prolactin has been evaluated below $0.6 \mathrm{ng} / \mathrm{mL}$.

\section{Statistical analysis}

For statistical analysis Excel 2007 and STATISTICA 9.0 were used. Continuous values were described by means of arithmetic mean, standard deviation and median. Statistical comparison of the results Mann-Whitney $U$ test and Kruskal-Wallis test were used. For the evaluation of statistical classification Fisher's exact test, $\mathrm{Chi}^{2}$ with Yates correction and logistic regression were applied. $P<0.05$ was assumed as the level of statistical significance.

\section{Ethical statement}

All subjects gave their informed consent for inclusion before they participated in the study. The study was conducted in accordance with the Declaration of Helsinki, and the protocol was approved by the Ethics Committee of the Medical University of Silesia (KNW/0022/KB1/8/11).

\section{RESULTS}

\section{Menstrual cycles}

The analysis of menstrual cycle disorders showed statistical significance for heavy menstrual bleeding $(p=0.01)$ and longer breaks between menstrual bleeds $(p=0.01)$. The study group was statistically more likely to suffer from hypermenorrhea and longer breaks in menstruation than the control group. For the remaining domains the differences were not statistically significant. The groups were homogenous in terms of the length of menstruation cycle and the severity of menstrual pain (Fig. 1).

\section{Premenstrual syndrome and premenstrual dysphoric disorder}

In accordance with APA and ACOG recommendations, PMDD was diagnosed in $8 \%$ and PMS in more than $42 \%$ of the whole research population. PMDD incidence did not significantly differ between the groups $(9.33 \%$ in the study group vs $6.0 \%$ in control group) as opposed to PMS incidence which was statistically different in both groups $(p=0.045)(49.33 \%$ in the study group vs $32.00 \%$ in control group) (Fig. 2). 


\begin{tabular}{|c|c|c|c|}
\hline & Studied group & Control group & \\
\hline $\begin{array}{l}\text { Irregular menstruation } \\
\text { periods } \mathrm{N}=49(100 \%)\end{array}$ & $55.10 \%$ & Test: NS $(p=0.45)$ & $44.90 \%$ \\
\hline $\begin{array}{l}\text { Painful menstruation } \\
\text { periods } N=107(100 \%)\end{array}$ & $57.94 \%$ & Test NS $(p=0.31)$ & $42.06 \%$ \\
\hline $\begin{array}{l}\text { Heavy menstruation } \\
\text { periods } N=50(100 \%)\end{array}$ & $74.00 \%$ & Test: $p=0.01$ & $26.00 \%$ \\
\hline $\begin{array}{l}\text { Other present disorders } \\
\qquad N=23(100 \%)\end{array}$ & $65.12 \%$ & Test: NS $(p=0.45)$ & $34.88 \%$ \\
\hline $\begin{array}{l}\text { Breakthrough bleeding } \\
\text { incidences } \mathrm{N}=23(100 \%)\end{array}$ & $73.91 \%$ & Test: NS $(p=0.16)$ & $26.09 \%$ \\
\hline $\begin{array}{l}\text { Longer breaks between } \\
\text { periods } N=42(100 \%)\end{array}$ & $76.19 \%$ & Test: $p=0.01$ & $23.81 \%$ \\
\hline
\end{tabular}

Figure 1. Abnormalities in the menstruation cycle in the study and control groups. NS - not significant

To validate the occurrence of various types of PMS and PMDD a premenstrual symptoms screening tool (PSST) was used. It proved the previous lack of PMS and PMDD in women without any clinical symptoms in both groups and differentiated PMS and PMDD into various scenarios, including mild and severe PMS and PMDD. In a significant percentage of women in the study group (37.33\%) and control group $(26.00 \%)$ a mild PMS was diagnosed. The differences between the groups were statistically insignificant (Fig. 3).
The analysis of selected parameters such as respondents' age, their BMI, age of menarche, years in sport, frequency of training or coffee, alcohol and cigarettes consumption indicates that some might be risk factors for PMS and PMDD.

The first investigated factors were subjects' age, BMI and menarche age. A one-way analysis did not show any significant influence of these variables on PMDD prevalence. However, it presented a significant correlation between PMS, average age $(p=0.00001)$ and menarche age $(p=0.03)$ in girls and young women who were professional athletes. The risk of PMS increased with age (by 1.71 with each year; $p=0.0007$ ).

There was nothing statistically significant between the number of years in sport and PMDD prevalence was observed. However, it must be noted that the greatest percentage of professional athletes suffering from PMDD practiced 2 years (28.57\%) and 7 years (28.57\%) (Fig 4.) (Tab. 2).

The incidence of PMS was, on the other hand, significantly associated with longer professional experience ( $p=0.0001)$ in the study group. The highest percentage of girls with PMS diagnosis was observed among women practicing 2 years (18.92\%) and 5 years (16.22\%) (Fig. 5).

No statistically significant correlation between weekly number of trainings and PMDD prevalence was shown in the studied group while the percentage of subjects with diagnosed PMS was increasing proportionally to the increasing number of trainings, with the highest value in case of 7 trainings per week ( $p=0.004$ ) (Fig. 6).

There was no statistically significant effect of coffee, alcohol or cigarettes on PMDD incidence in either group

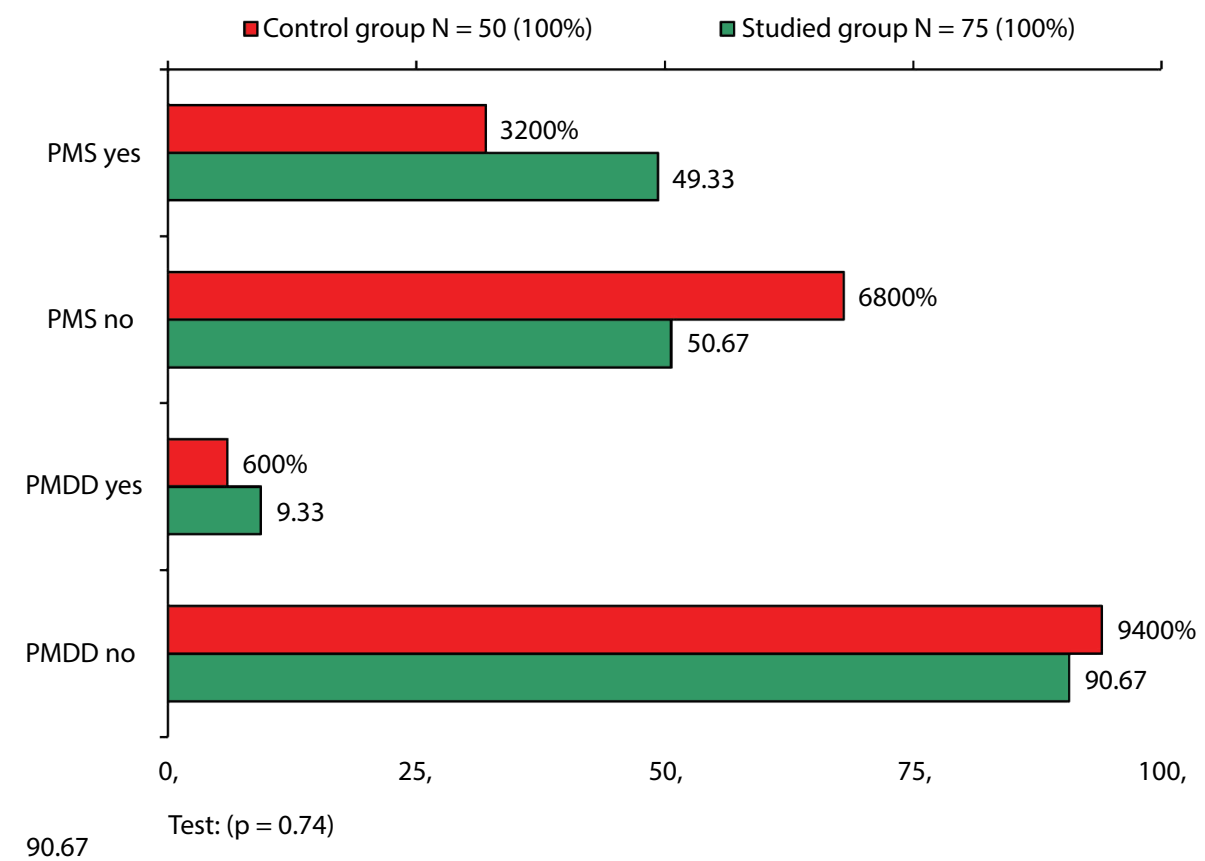

Figure 2. PMS and PMDD diagnosed according American Psychiatric Association and American College of Obstetricians and Gynecologists recommendations in both groups. PMDD — premenstrual dysphoric order; PMS — premenstrual syndrome 
(Tab. 3), however, higher frequency of PMS was noted in respondents who took coffee and alcohol more frequently and in greater amount (more than 3 cups of coffee per day and more than $500 \mathrm{~mL}$ of beer or 2 glasses of wine of $50 \mathrm{~mL}$ of stronger alcohol). No impact of cigarettes has been noted and none of the above correlations have been observed in the control group (Tab. 4).

Neither the regularity of meals nor weight-reducing diet had any statistically significant impact on the prevalence of PMS and PMDD in two groups.

\section{Clinical analysis of selected sex hormones}

Long-lasting periods of physical strain in women engaged in competitive sports can temporarily impair the hormonal function of the ovaries. Therefore, the researchers decided to investigate whether excessive physical activity reduced the concentration of gonadotropins, estrogens and prolactin in women.

The study $(\mathrm{N}=75)$ and control $(\mathrm{N}=50)$ groups were homogenous in terms of $\mathrm{FSH}, \mathrm{LH}$, prolactin and estradiol levels determined in the first phase of menstrual cycle. Hormone levels in case of PMS were analysed. LH level was statistically different $(p=0.02)$ in patients with PMS in the control group. However, it does not seem to be of clinical relevance (Tab. 5 and 6).

Statistically significant correlation between the number of trainings and the level of estradiol was shown, with the lowest value in the case of 4 trainings per week $(p=0.03)$. The level of prolactin was statistically significant for the overall number of training hours per week $(p=0.003)$. The lowest prolactin level was obtained in girls practicing 12 hours a week. The findings from this study may encourage more

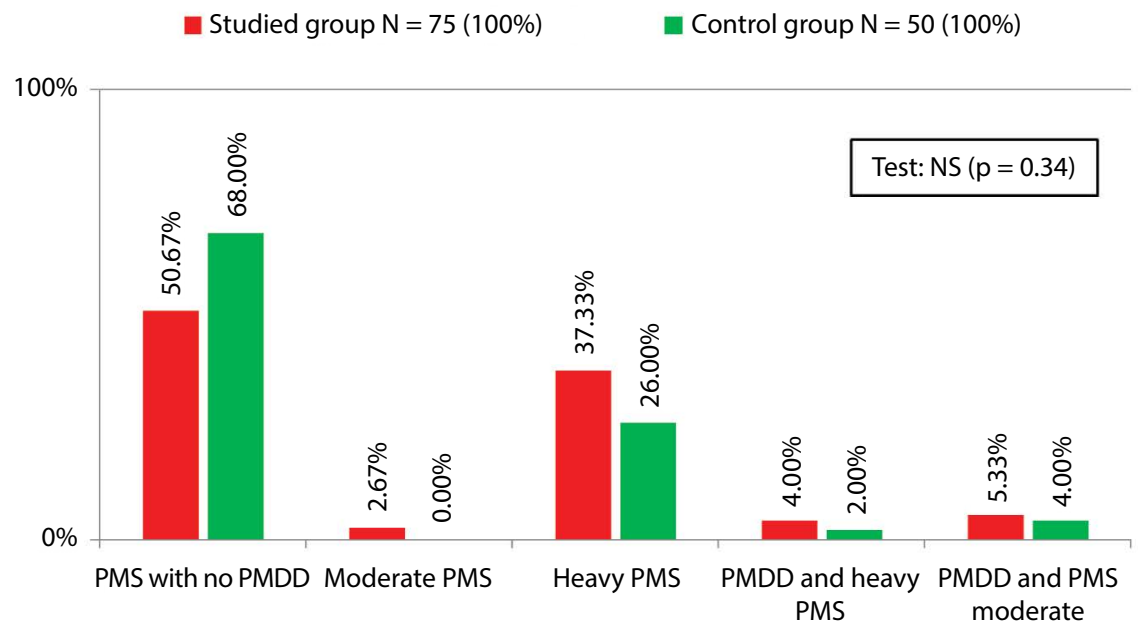

Figure 3. Premenstrual symptoms screening tool results in both groups. NS — not significant; PMDD — premenstrual dysphoric order; PMS - premenstrual syndrome

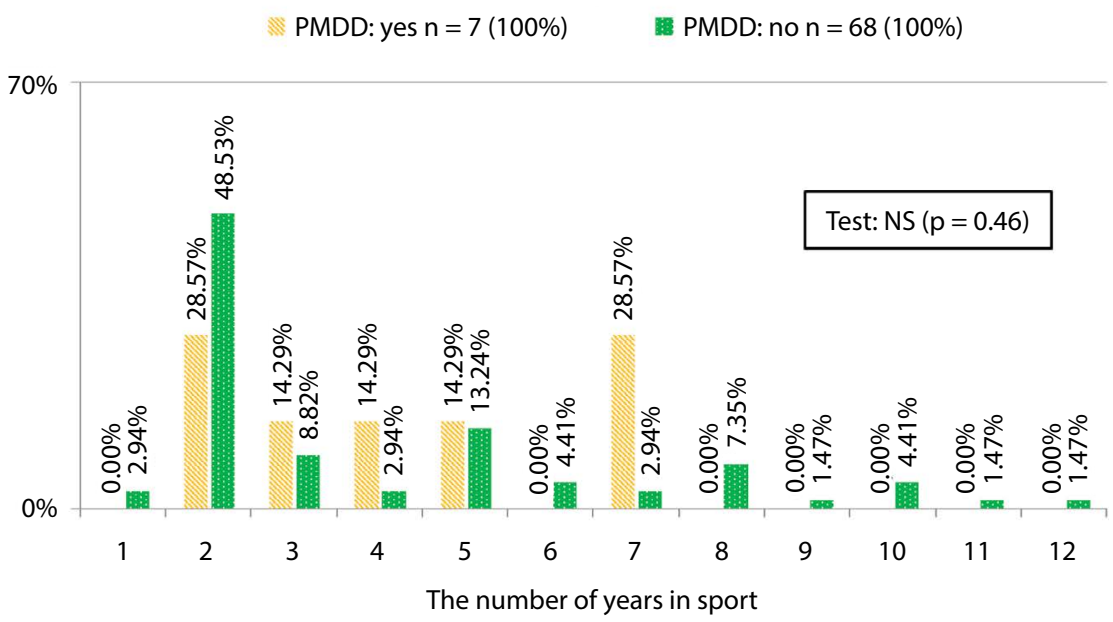

Figure 4. The correlation between PMDD and the number of years in sport. NS — not significant; PMDD — premenstrual dysphoric order 
Table 2. Age, BMI and menarche in the study and control groups

\begin{tabular}{|c|c|c|c|c|c|c|c|}
\hline \multicolumn{8}{|c|}{ Study group } \\
\hline Values & PMDD & Mean & Standard deviation & Median & $5^{\text {th }}$ percentile & $95^{\text {th }}$ percentile & $\begin{array}{l}\text { Mann-Whitney's } \\
\text { U test }\end{array}$ \\
\hline \multirow{2}{*}{ Age [years] } & Yes & 19.7 & 2.0 & 20.0 & 17.0 & 21.7 & \multirow{2}{*}{ NS $(p=0.14)$} \\
\hline & No & 18.5 & 1.9 & 17.5 & 16.0 & 21.0 & \\
\hline \multirow{2}{*}{ BMI } & Yes & 20.77 & 1.97 & 19.67 & 18.99 & 23.49 & \multirow{2}{*}{ NS $(p=0.49)$} \\
\hline & No & 19.93 & 1.80 & 19.92 & 16.84 & 22.38 & \\
\hline \multirow{2}{*}{ Menarche } & Yes & 13.4 & 2.0 & 13.0 & 11.3 & 16.4 & \multirow{2}{*}{ NS $(p=0.86)$} \\
\hline & No & 13.3 & 1.3 & 13.0 & 11.0 & 15.0 & \\
\hline \multicolumn{8}{|c|}{ Control group } \\
\hline Values & PMDD & Mean & Standard deviation & Median & $5^{\text {th }}$ percentile & $95^{\text {th }}$ percentile & $\begin{array}{l}\text { Mann-Whitney's } \\
\text { U test }\end{array}$ \\
\hline \multirow{2}{*}{ Age [years] } & Yes & 20.0 & 0.0 & 20.0 & 20.0 & 20.0 & \multirow{2}{*}{ NS $(p=0.20)$} \\
\hline & No & 18.4 & 1.8 & 20.0 & 16.0 & 20.7 & \\
\hline \multirow{2}{*}{ BMI } & Yes & 20.32 & 1.30 & 20.98 & 19.04 & 21.14 & \multirow{2}{*}{ NS $(p=0.29)$} \\
\hline & No & 21.93 & 2.68 & 21.46 & 18.04 & 26.51 & \\
\hline \multirow{2}{*}{ Menarche } & Yes & 13.0 & 1.0 & 13.0 & 12.1 & 13.9 & \multirow{2}{*}{ NS $(p=0.83)$} \\
\hline & No & 12.9 & 1.2 & 13.0 & 11.0 & 15.0 & \\
\hline
\end{tabular}

\begin{tabular}{|c|c|c|c|c|c|c|c|}
\hline \multicolumn{8}{|c|}{ Study group } \\
\hline Values & PMS & Mean & Standard deviation & Median & $5^{\text {th }}$ percentile & $95^{\text {th }}$ percentile & $\begin{array}{l}\text { Mann-Whitney's } \\
\text { U test }\end{array}$ \\
\hline \multirow{2}{*}{ Age [years] } & Yes & 19.6 & 1.7 & 20.0 & 17.0 & 22.0 & \multirow{2}{*}{$p=0.00001$} \\
\hline & No & 17.7 & 1.7 & 17.0 & 16.0 & 21.0 & \\
\hline \multirow{2}{*}{ BMI } & Yes & 19.76 & 2.18 & 19.69 & 16.43 & 23.91 & \multirow{2}{*}{ NS $(p=0.22)$} \\
\hline & No & 20.24 & 1.37 & 20.11 & 18.19 & 22.07 & \\
\hline \multirow{2}{*}{ Menarche } & Yes & 13.7 & 1.6 & 13.0 & 11.8 & 17.2 & \multirow{2}{*}{$p=0.03$} \\
\hline & No & 12.9 & 1.1 & 13.0 & 11.0 & 14.0 & \\
\hline \multicolumn{8}{|c|}{ Control group } \\
\hline Values & PMS & Mean & Standard deviation & Median & $5^{\text {th }}$ percentile & $95^{\text {th }}$ percentile & $\begin{array}{l}\text { Mann-Whitney's } \\
\text { U test }\end{array}$ \\
\hline \multirow{2}{*}{ Age [years] } & Yes & 18.5 & 1.8 & 20.0 & 16.0 & 20.0 & \multirow{2}{*}{ NS $(p=0.90)$} \\
\hline & No & 18.5 & 1.9 & 20.0 & 16.0 & 21.0 & \\
\hline \multirow{2}{*}{ BMI } & Yes & 21.19 & 1.39 & 21.08 & 18.98 & 22.84 & \multirow{2}{*}{ NS $(p=0.41)$} \\
\hline & No & 22.14 & 3.03 & 21.63 & 17.79 & 27.64 & \\
\hline \multirow{2}{*}{ Menarche } & Yes & 13.8 & 1.3 & 13.0 & 11.8 & 15.0 & \multirow{2}{*}{ NS $(p=0.06)$} \\
\hline & No & 12.6 & 1.1 & 13.0 & 11.0 & 14.0 & \\
\hline
\end{tabular}

$\mathrm{BMI}$ — body mass index; PMDD — premenstrual dysphoric order; PMS — premenstrual syndrome; NS — not significant

research into other hormones, such as testosterone, which was not investigated for this study, as none of the subjects manifested any androgenized features.

\section{DISCUSSION}

Following recent increase in the number of female athletes and expansion of female competitions there has been a great focus on supporting active girls and young women and improve their competitiveness [15]. Without opposition, numerous researchers highlight that a note- worthy percentage of women engaged in various sport disciplines is afflicted by disorders of the menstruation cycle. So far, the greatest number of studies on the frequency of amenorrhea and oligomenorrhea have focused mostly on long-distance runners, marathon runners, gymnasts, swimmers and women whose profession also involved intensive physical activity, such as ballet dancers [16]. In the population of Polish sportswomen, menstruation cycle disorders have been investigated in female sprinters, rowers, canoers, judokas, fencers, basketball and handball players $[17,18]$. 


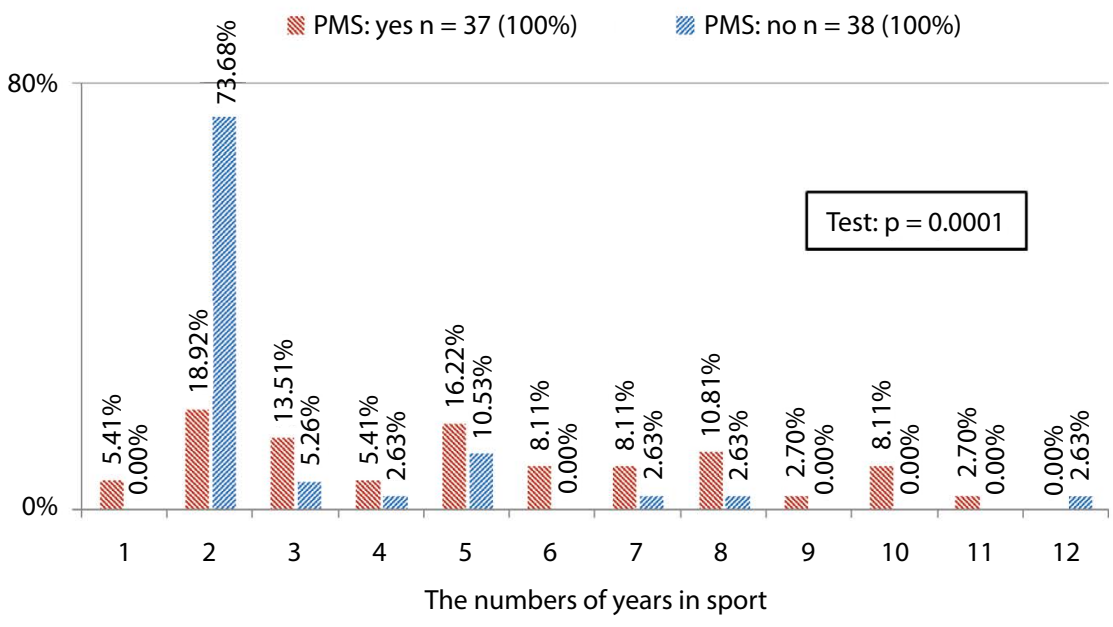

Figure 5. The correlation between PMS and the number of years in sport. PMS — premenstrual syndrome

The number of training days per week

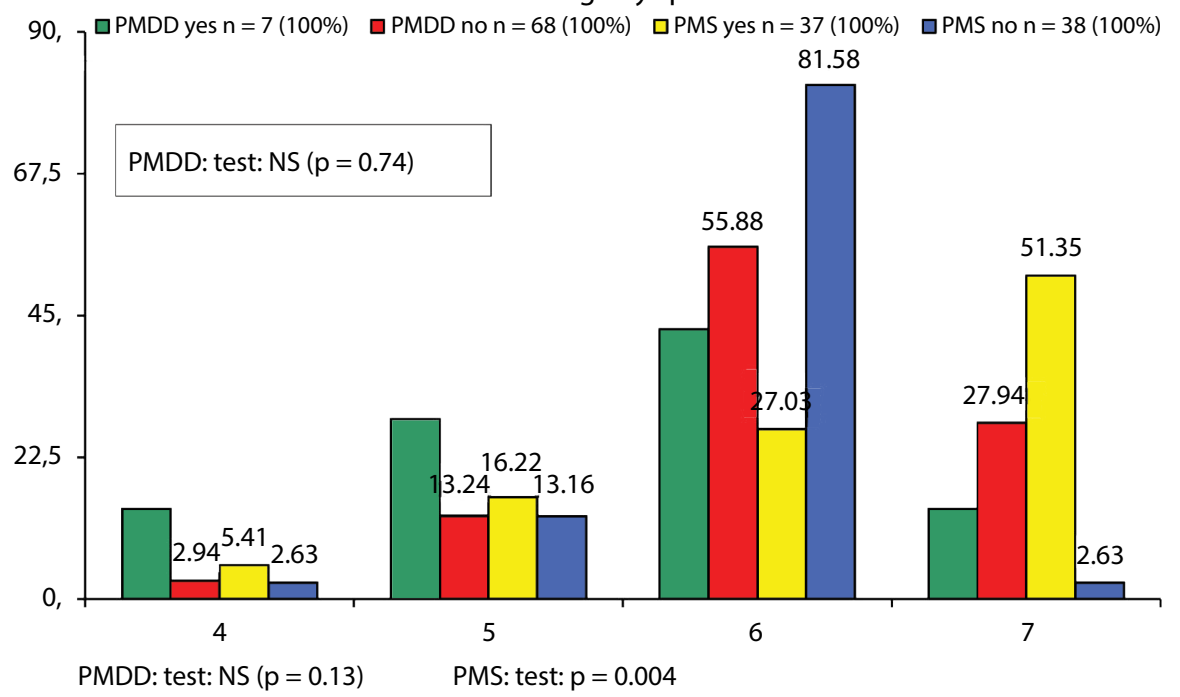

Figure 6. PMS and PMDD versus the frequency of training. NS — not significant; PMDD — premenstrual dysphoric order; PMS - premenstrual syndrome

This research involved professional young female athletes, including medium and long distance-runners. It showed significantly longer breaks between menses $(p=0.01)$ in women practicing sports as compared to women who didn't practice any sport. The situation was similar in case of hypermenorrhea $(p=0.01)$. The remaining abnormalities such as irregular and painful menses were specific to more than a half of respondents who were active in sports.

It should be noted that consequences of menstrual dysfunction might manifest as suppression of reproductive hormones and infertility, altered cardio-vascular risk factors (e.g. lipid profile, endothelial function) and lower BMD (bone mineral density). Considering the fact that the consequences of menstrual dysfunction on BMD may not be reversible in every respect, evaluation of bone health should be considered if menstrual disorders are prolonged [19]. Coaches and clinicians should also remember that female youth and adolescent athletes are at greater risk for certain types of injuries, including concussions, musculoskeletal injury and Female Athlete Triad, which consists of low energy availability with or without disordered eating, menstrual dysfunction and low bone mineral density [20]. Therefore, the etiology of menstrual dysfunction must be always considered multi-factorial and thoroughly investigated.

Numerous studies showed fully diagnosed PMDD in $3-8 \%$ of women at reproduction age [21-25]. Robinson and Swindle confirmed an even significantly higher percentage 


\begin{tabular}{|c|c|c|c|c|c|c|c|}
\hline \multirow{3}{*}{ Type of stimulant } & \multirow{3}{*}{ Frequency } & \multicolumn{3}{|c|}{ Study group } & \multicolumn{3}{|c|}{ Control group } \\
\hline & & \multicolumn{2}{|c|}{ PMDD } & \multirow{2}{*}{ Test } & \multicolumn{2}{|c|}{ PMDD } & \multirow{2}{*}{ Test } \\
\hline & & No & Yes & & No & Yes & \\
\hline \multirow{2}{*}{ Coffee } & Does not drink & 41 & 5 & \multirow{2}{*}{ NS $(p=0.70)$} & 18 & 1 & \multirow{2}{*}{ NS $(p=1.00)$} \\
\hline & Drinks & 27 & 2 & & 29 & 2 & \\
\hline \multirow{2}{*}{ Cigarettes } & Does not smoke & 66 & 6 & \multirow{2}{*}{ NS $(p=0.26)$} & 41 & 2 & \multirow{2}{*}{$\mathrm{NS}(p=0.57)$} \\
\hline & Smokes & 2 & 1 & & 6 & 1 & \\
\hline \multirow{3}{*}{ Alcohol } & Does not drink at all & 30 & 2 & \multirow{3}{*}{ NS $(p=0.21)$} & 11 & 0 & \multirow{3}{*}{ NS $(p=0.22)$} \\
\hline & Drinks but only to give a toast & 34 & 3 & & 28 & 3 & \\
\hline & Drinks on regular basis & 4 & 2 & & 8 & 0 & \\
\hline
\end{tabular}

NS - not significant; PMDD — premenstrual dysphoric order

\begin{tabular}{|c|c|c|c|c|c|c|c|}
\hline \multirow{3}{*}{ Type of stimulant } & \multirow{3}{*}{ Frequency } & \multicolumn{3}{|c|}{ Study group } & \multicolumn{3}{|c|}{ Control group } \\
\hline & & \multicolumn{2}{|c|}{ PMS } & \multirow{2}{*}{ Test } & \multicolumn{2}{|c|}{ PMS } & \multirow{2}{*}{ Test } \\
\hline & & No & Yes & & No & Yes & \\
\hline \multirow{2}{*}{ Coffee } & Does not drink & 28 & 18 & \multirow{2}{*}{$p=0.03$} & 10 & 9 & \multirow{2}{*}{$\mathrm{NS}(p=0.12)$} \\
\hline & Drinks & 10 & 19 & & 24 & 7 & \\
\hline \multirow{2}{*}{ Cigarettes } & Does not smoke & 37 & 35 & \multirow{2}{*}{ NS $(p=0.61)$} & 29 & 14 & \multirow{2}{*}{ NS $(p=1.00)$} \\
\hline & Smokes & 1 & 3 & & 5 & 2 & \\
\hline \multirow{3}{*}{ Alcohol } & Does not drink at all & 21 & 11 & \multirow{3}{*}{$p=0.03$} & 9 & 2 & \multirow{3}{*}{ NS $(p=0.13)$} \\
\hline & Drinks but only to give a toast & 16 & 21 & & 18 & 13 & \\
\hline & Drinks on regular basis & 1 & 5 & & 7 & 1 & \\
\hline
\end{tabular}

NS - not significant; PMS — premenstrual syndrome

\begin{tabular}{|c|c|c|c|c|c|c|c|c|}
\hline \multirow{2}{*}{ Hormone } & \multirow{2}{*}{ Group } & \multirow{2}{*}{ PMDD } & \multicolumn{5}{|c|}{ Descriptive statistics } & \multirow{2}{*}{ Mann-Whitney's U test } \\
\hline & & & Mean & Median & SD & $5^{\text {th }}$ percentile & $95^{\text {th }}$ percentile & \\
\hline \multirow{4}{*}{$\begin{array}{l}\text { FSH } \\
{[\mathrm{m} \mathrm{IU} / \mathrm{mL}]}\end{array}$} & \multirow{2}{*}{ Studied } & Yes & 4.54 & 4.30 & 1.04 & 2.69 & 5.70 & \multirow{2}{*}{ NS $(p=0.36)$} \\
\hline & & No & 5.01 & 5.03 & 1.17 & 2.66 & 6.67 & \\
\hline & \multirow{2}{*}{ Control } & Yes & 5.78 & 6.06 & 0.70 & 4.99 & 6.30 & \multirow{2}{*}{ NS $(p=0.93)$} \\
\hline & & No & 5.65 & 5.88 & 1.59 & 3.21 & 6.81 & \\
\hline \multirow{4}{*}{$\begin{array}{l}\mathrm{LH} \\
{[\mathrm{m} \mathrm{IU} / \mathrm{mL}]}\end{array}$} & \multirow{2}{*}{ Studied } & Yes & 2.73 & 2.26 & 1.41 & 1.07 & 5.22 & \multirow{2}{*}{$\mathrm{NS}(p=0.30)$} \\
\hline & & No & 3.30 & 2.48 & 1.53 & 1.45 & 5.29 & \\
\hline & \multirow{2}{*}{ Control } & Yes & 4.03 & 2.88 & 2.06 & 2.80 & 6.41 & \multirow{2}{*}{$\mathrm{NS}(\mathrm{p}=0.90)$} \\
\hline & & No & 3.92 & 3.31 & 1.97 & 1.38 & 7.81 & \\
\hline \multirow{4}{*}{$\begin{array}{l}\text { Estradiol } \\
{[\mathrm{pg} / \mathrm{mL}]}\end{array}$} & \multirow{2}{*}{ Studied } & Yes & 43.61 & 38.10 & 13.52 & 33.60 & 68.30 & \multirow{2}{*}{ NS $(p=0.47)$} \\
\hline & & No & 50.28 & 45.90 & 28.11 & 8.80 & 74.20 & \\
\hline & \multirow{2}{*}{ Control } & Yes & 45.87 & 43.60 & 4.37 & 43.10 & 50.90 & \multirow{2}{*}{ NS $(p=0.61)$} \\
\hline & & No & 47.35 & 42.30 & 16.71 & 30.40 & 73.10 & \\
\hline \multirow{4}{*}{$\begin{array}{l}\text { Prolactin } \\
{[\mathrm{ng} / \mathrm{mL}]}\end{array}$} & \multirow{2}{*}{ Studied } & Yes & 9.48 & 7.79 & 3.76 & 6.27 & 14.53 & \multirow{2}{*}{$\mathrm{NS}(p=0.16)$} \\
\hline & & No & 17.22 & 10.71 & 23.49 & 3.78 & 40.76 & \\
\hline & \multirow{2}{*}{ Control } & Yes & 12.49 & 9.01 & 7.05 & 7.86 & 20.61 & \multirow{2}{*}{$\mathrm{NS}(\mathrm{p}=0.28)$} \\
\hline & & No & 9.41 & 7.97 & 4.69 & 5.00 & 17.40 & \\
\hline
\end{tabular}

NS — not significant; PMDD — premenstrual dysphoric order 


\begin{tabular}{|c|c|c|c|c|c|c|c|c|}
\hline \multirow{2}{*}{ Hormone } & \multirow{2}{*}{ Group } & \multirow{2}{*}{ PMS } & \multicolumn{5}{|c|}{ Descriptive statistics } & \multirow{2}{*}{ Mann-Whitney's U test } \\
\hline & & & Mean & Median & SD & $5^{\text {th }}$ percentile & $95^{\text {th }}$ percentile & \\
\hline \multirow{4}{*}{$\begin{array}{l}\text { FSH } \\
{[\mathrm{m} \mathrm{IU} / \mathrm{mL}]}\end{array}$} & \multirow{2}{*}{ Studied } & Yes & 4.85 & 4.84 & 1.45 & 2.28 & 8.84 & \multirow{2}{*}{ NS $(p=0.23)$} \\
\hline & & No & 5.08 & 5.04 & 0.79 & 4.04 & 6.67 & \\
\hline & \multirow{2}{*}{ Control } & Yes & 5.73 & 5.91 & 0.84 & 4.08 & 6.81 & \multirow{2}{*}{ NS $(p=0.54)$} \\
\hline & & No & 5.62 & 5.82 & 1.79 & 2.74 & 7.21 & \\
\hline \multirow{4}{*}{$\begin{array}{l}\text { LH } \\
{[\mathrm{m} \mathrm{IU} / \mathrm{mL}]}\end{array}$} & \multirow{2}{*}{ Studied } & Yes & 2.87 & 2.34 & 1.62 & 0.95 & 5.43 & \multirow{2}{*}{$p=0.02$} \\
\hline & & No & 3.61 & 3.36 & 1.32 & 1.96 & 5.29 & \\
\hline & \multirow{2}{*}{ Control } & Yes & 4.47 & 4.21 & 2.10 & 1.38 & 7.83 & \multirow{2}{*}{$\mathrm{NS}(p=0.22)$} \\
\hline & & No & 3.67 & 3.11 & 1.86 & 0.64 & 7.67 & \\
\hline \multirow{4}{*}{$\begin{array}{l}\text { Estradiol } \\
{[\mathrm{pg} / \mathrm{mL}]}\end{array}$} & \multirow{2}{*}{ Studied } & Yes & 49.95 & 39.8 & 35.76 & 4.10 & 178.0 & \multirow{2}{*}{ NS $(p=0.35)$} \\
\hline & & No & 49.37 & 45.9 & 15.06 & 28.00 & 74.20 & \\
\hline & \multirow{2}{*}{ Control } & Yes & 46.68 & 43.60 & 13.67 & 28.50 & 73.10 & \multirow{2}{*}{ NS $(p=0.86)$} \\
\hline & & No & 47.53 & 42.10 & 17.47 & 31.20 & 73.20 & \\
\hline \multirow{4}{*}{$\begin{array}{l}\text { Prolactin } \\
{[\mathrm{ng} / \mathrm{mL}]}\end{array}$} & \multirow{2}{*}{ Studied } & Yes & 20.27 & 13.89 & 30.35 & 3.78 & 141.5 & \multirow{2}{*}{$\mathrm{NS}(p=0.25)$} \\
\hline & & No & 12.82 & 10.42 & 9.35 & 3.78 & 40.76 & \\
\hline & \multirow{2}{*}{ Control } & Yes & 9.02 & 7.86 & 3.64 & 5.18 & 20.61 & \multirow{2}{*}{$\mathrm{NS}(p=0.73)$} \\
\hline & & No & 9.86 & 7.97 & 5.31 & 4.39 & 22.91 & \\
\hline
\end{tabular}

NS — not significant; PMS — premenstrual syndrome

(exceeding 16\%) of women with diagnosed PMDD [21]. Epidemiologic studies indicate that $15-20 \%$ of menstruating women meet PMS criteria. The recognition rate is about $50 \%$ in women of reproductive age and $50-80 \%$ in girls $[21,26,27]$. However, this study is the first to confirm PMS frequency in active sportswomen according to ACOG criteria and to identify risk factors predisposing for both PMS and PMDD.

In accordance with APA and ACOG recommendations, PMDD was diagnosed in $8 \%$ and PMS in more than $42 \%$ of the whole research population. The study presented a significant correlation between PMS, average age $(p=0.00001)$ and menarche age $(p=0.03)$ in girls and young women who were professional athletes. The risk of PMS increased with age (by 1.71 with each year) $(p=0.0007)$. The incidence of PMS was also significantly associated with longer professional experience $(p=0.0001)$ in the study group and was significantly increasing proportionally to the increasing number of trainings, with the highest value in case of 7 trainings per week $(p=0.004)$. Higher frequency of PMS was noted in respondents who drank coffee and alcohol more frequently and in greater amount. These findings may encourage more research into other risk factors such as body composition, nutrition or psychological factors.

Hormone levels in sportswomen have also been evaluated by numerous researchers. The recent studies claim that the concentration of prolactin may rise under the influence of physical effort (as opposed to energetic deficiency) but this phenomenon is not likely to cause menstruation distur- bances in physically active women. They also showed that prolactin levels are subject to minor short-term changes throughout the cycle and prolactin concentration in sportswomen with amenorrhea does not significantly differ from the prolactin concentration in menstruating women who do not practice any sport [28-33]. However, studies by both Bielecka et al. and Męczekalski et al. showed an increased prolactin level in female professional athletes, who were exposed to physical and psychological stress during sport competitions [30, 31, 34, 35]. This research showed that study and control groups were homogenous in terms of $\mathrm{FSH}, \mathrm{LH}$, prolactin and estradiol levels determined in the first phase of menstrual cycle, however it should be noted that it involved only single determination of prolactin levels. Daily concentration profiles might be more reliable, but they were not carried out in this study.

This study has been also limited by the relatively small number of subjects, thus it cannot be related to the whole population of sportswomen unless further extended and the results are significantly dependent on the specific questionnaire which is based on the respondents' subjective evaluation of the reported symptoms.

However, in none of the previously conducted studies was it ever attempted to verify the effects the physical effort made while engaging in competitive sports on the rate of occurrence of PMS as well as PMDD with accordance to APA and ACOG criteria. That is why the juxtaposition of daily prospective assessment of PMS and PMDD symptoms and 
the application of the screening tool for premenstrual symptoms (PSST) prove to be a genuinely innovative approach.

Findings from this research may encourage more research into menstrual dysfunctions in female athletes to increase the awareness of their coaches and clinicians, who can better support them in enjoying full benefits of sport participation.

\section{CONCLUSIONS}

Age, menarche age, the number of years in sport and the intensity of trainings increase the risk of PMS occurrence in young female athletes. The risk of PMDD is increasing with the age of girls who train intensively. The amount of consumed alcohol and coffee are significant risk factors for premenstrual tension syndrome and premenstrual dysphoric disorder in female athletes.

\section{Author contributions}

For research articles with several authors, a short paragraph specifying their individual contributions must be provided. The following statements should be used "conceptualization, MC and AD-C; data curation, MC, IG, CG, and BN; writing - original draft preparation, MC, IG, and CG; writing — review and editing, AD-C, MR, and VS-P.

\section{Conflict of interest}

No competing financial interests exist. The authors report no financial, personal, political, intellectual or religious conflicts of interest. The authors alone are responsible for the content and writing of the paper.

\section{REFERENCES}

1. Wheatley S, Khan S, Székely A, et al. Expanding the female athlete triad concept to address a public health issue. Performance Enhancement \& Health. 2012; 1(1): 10-27, doi: 10.1016/j.peh.2012.03.001.

2. Brook Ch. (ed). Endokrynologia pediatryczna. Elsevier Ubran\&Partner, Wrocław 2013: 37-95, 139-162.

3. Lebrun C. The female athlete triad. Women's Health Medicine. 2006; 3(3): 119-123, doi: 10.1383/wohm.2006.3.3.119.

4. Brown K, Dewoolkar A, Baker N, et al. The female athlete triad: special considerations for adolescent female athletes. Translational Pediatrics. 2017; 6(3): 144-149, doi: 10.21037/tp.2017.04.04.

5. Skrzypulec-Plinta V., Drosdzol-Cop A. (ed). Ginekologia dziecięca i dziewczęca. PZWL, Warszawa 2017: 49-76, 107-145, 183-203.

6. Gordon C, Ackerman K, Berga S, et al. Functional hypothalamic amenorrhea: an endocrine society clinical practice guideline. J Clin Endocrinol Metab. 2017; 102(5): 1413-1439, doi: 10.1210/jc.2017-00131.

7. American College of Obstericians and Gynecologists. ACOG practice bulletin: management of anowvulatory bleeding. ACOG Committee on Practice Bulletins — Gynecology. Int J Gynaecol Obstet. 2001; 72(3): 263-271.

8. Halbreich U, Backstrom T, Eriksson E, et al. Clinical diagnostic criteria for premenstrual syndrome and guidelines for their quantification for research studies. Gynecological Endocrinology. 2009; 23(3): 123-130, doi: 10.1080/09513590601167969.

9. Gehlert $\mathrm{S}$, Song $\mathrm{IH}$, Chang $\mathrm{CH}$, et al. The prevalence of premenstrual dysphoric disorder in a randomly selected group of urban and rural women. Psychological Medicine. 2008; 39(1): 129-136, doi: 10.1017/s003329170800322x.

10. Adewuya AO, Loto OM, Adewumi TA. Premenstrual dysphoric disorder amongst Nigerian university students: prevalence, comorbid conditions, and correlates. Archives of Women's Mental Health. 2008; 11(1): 13-18, doi: 10.1007/s00737-008-0213-4.

11. Czajkowska M, Drosdzol-Cop A, Gałazka I, et al. Menstrual cycle and the prevalence of premenstrual syndrome/premenstrual dysphoric disorder in adolescent athletes. J Pediatr Adolesc Gynecol. 2015; 28(6): 492-498, doi: 10.1016/j.jpag.2015.02.113.

12. Gałecki P, Święcicki Ł. (ed.) Kryteria diagnostyczne z DSM-5. Edra Urban \& Partner, Wrocław 2015.

13. American College of Obstericians and Gynecologists. ACOG practice bulletin: management of anowulatory bleeding. ACOG Committee on Practice Bulletins - Gynecology. Int J Gynaecol Obstet. 2001; 72(3): 263-271.

14. American Psychiatric Association. Premenstrual dysphoric disorder. In Diagnostic and Statistical Manual of Mental Disorders, Fourth Edition, Text Revision. American Psychiatric Association, Washington 2000: 771-774.

15. Sowińska-Przepiera E, Andrysiak-Mamos E, Jarzabek-Bielecka G, et al. Functional hypothalamic amenorrhoea - diagnostic challenges, monitoring and treatment. Endokrynol Pol. 2015; 66(3): 252-260.

16. Ducher G, Eser P, Hill B, et al. History of amenorrhoea compromises some of the exercise-induced benefits in cortical and trabecular bone in the peripheral and axial skeleton: A study in retired elite gymnasts. Bone. 2009; 45(4): 760-767, doi: 10.1016/j.bone.2009.06.021.

17. Drosdzol-Cop A, Skrzypulec-Plinta V. Komentarz do aktykułu pt. Co jest normą? Dokładna i efektywna ocena miesiączkowania. Med Prakt Pediatr. 2016; 2: 88-89.

18. Yermachenko A, Dvornyk V. Nongenetic determinants of age at menarche: a systematic review. Biomed Res Int. 2014; 2014: 1-14, doi: 10.1155/2014/371583.

19. Williams $C$, Creighton S. Menstrual disorders in adolescents: review of current practice. Horm Res Pediatr. 2012; 78(3): 135-143, doi: $10.1159 / 000342822$.

20. Pantano K. Knowledge, attitude, and skill of high school coaches with regard to the female athlete triad. J Pediatr Adolesc Gynecol. 2017; 30(5): 540-545, doi: 10.1016/j.jpag.2016.09.013.

21. Nattiv A, Loucks AB, Manore MM, et al. American College of Sports Medicine position stand. The female athlete triad. Med Sci Sports Exerc. 2007; 39(10): 1867-1882.

22. Loveless M, Hewitt G. Committee Opinion No. 702: Female Athlete Triad. Obstetrics and Gynecology. 2017; 129(6): 160-167.

23. Yermachenko A, Dvornyk V. Nongenetic determinants of age at menarche: a systematic review. Biomed Res Int. 2014; 2014: 1-14, doi: 10.1155/2014/371583.

24. Caronia L, Martin C, Welt $C$, et al. A genetic basis for functional hypothalamic amenorrhea. N Engl J Med. 2011; 364(3): 215-225, doi: 10.1056/nejmoa0911064.

25. Gelson E, Prakash A. Investigation and treatment of primary amenorrhoea. Obster Ginecol and Reproduct Med. 2016; 26(4): 108-113, doi: 10.1016/j.ogrm.2016.01.004

26. Zgliszczyński W. red. Endokrynologia 2. Wielka Interna, Warszawa 2012: 533-593.

27. Haamid F, Sass A, Dietrich J. Heavy menstrual bleeding in adolescents. J Pediatr Adolesc Gynecol. 2017; 30(3): 335-340, doi: 10.1016/j. jpag.2017.01.002

28. Mallison RJ. De Suoza M.J. Current perspectives on the etiology and manifestation of the "silent" component of the Female Athlete Triad. International Journal of Women's Health. 2014; 6: 451-467.

29. Thein-Nissenbaum J. Long term consequences of the female athlete triad. Maturitas. 2013;75(2): 107-112, doi: 10.1016/j.maturitas.2013.02.010.

30. Guebels C, Kam L, Maddalozzo G, et al. Active women before/after an intervention designed to restore menstrual function: resting metabolic rate and comparison of four methods to quantify energy expenditure and energy availability. Int J Sport Nutr Exerc Metab. 2014; 24(1): 37-46, doi: 10.1123/ijsnem.2012-0165.

31. Fideleff HL, Boquete HR, Suárez MG, et al. Prolactinoma in children and adolescents. Horm Res. 2009; 72(4): 197-205, doi: 10.1159/000236081.

32. Brunet M. Female athlete triad. Clin Sports Med. 2005; 24(3): 623-636, doi: 10.1016/j.csm.2005.03.009.

33. Ciocca M. Medication and supplement use by athletes. Clin Sports Med. 2005; 24(3): 719-738, doi: 10.1016/j.csm.2005.03.005.

34. Bielecka-Jarząbek G, Radomski D, Nowaczyk A, et al. Analiza stężeń prolaktyny u dziewcząt bez cech endokrynopatii z zaburzeniami miesiączkowania i stresem w wywiadzie. Ginekol Prakt. 2010; 18(1):46-53.

35. Męczekalski B, Katulski K, Kostrzak A. Metabolicaspects of hyperprolactinaemia. Arch. Perinat. Med. 2012 Vol. Arch Perinat Med. 2012; 18(3): 153-156. 